\title{
Mixed systemic amyloidosis in a patient receiving long term haemodialysis
}

\author{
J Fernandez-Alonso, C Rios-Camacho, A Valenzuela-Castaño, W Hernanz-Mediano
}

\begin{abstract}
A 64 year old woman had been receiving haemodialysis for 11 years. She had a history of chronic renal failure, caused by probable chronic pyelonephritis, and dialysis arthropathy. She died of acute pulmonary oedema and haemorrhage. At necropsy, histological, immunohistochemical, and ultrastructural studies showed widespread visceral deposits of $\beta_{2}$-microglobulin $\left(\beta_{2}-M\right)$ and $A A$ amyloid.
\end{abstract}

(F Clin Pathol 1994;47:560-561)

Beta ${ }_{2}$-microglobulin $\left(\beta_{2}-\mathrm{M}\right)$ amyloidosis that predominantly affects perineural and periarticular structures, joints, and bone is common in patients receiving long term haemodialysis. ${ }^{1}$ Systemic deposits of $\beta_{2}-\mathrm{M}$ amyloid have also been reported. Initially, these findings were considered clinically unimportant. ${ }^{2}$ Subsequently, however, some investigators showed that extra-articular deposits of $\beta_{2}-\mathrm{M}$ amyloid can cause serious clinical problems. ${ }^{34}$ On the other hand, non- $\beta_{2}-\mathrm{M}$ type amyloidosis also appears in patients receiving haemodialysis, and this is generally attributed to concomitant disease. ${ }^{25}$

We report a patient who had been receiving haemodialysis for 11 years with dialysis associated amyloid arthropathy in whom a post mortem examination showed systemic deposits of $\mathrm{AA}$ and $\beta_{2}-\mathrm{M}$ amyloid.

\section{Case report}

A 64 year old woman with no history of tuberculosis, multiple myeloma, malignancy, osteomyelitis, bronchiectasis, chronic inflammatory bowel disease, or articular inflammatory disease, was diagnosed with end stage renal failure for probable chronic pyelonephritis in 1978. She required haemodialysis from December 1979. In March 1988 she received right-sided carpal tunnel decompression for carpal tunnel syndrome. A biopsy specimen obtained at the operation showed amyloid deposits of $\beta_{2}-\mathrm{M}$ type. During the same year a parathyroidectomy was performed because of secondary hyperparathyroidism. Two abdominal fat biopsy specimens taken in 1988 and 1989 showed no amyloid deposits. In 1990 she had recurring infections of the arteriovenous fistule for seven months. She died that year because of acute pulmonary oedema and intestinal bleeding.

The principal macroscopic findings were: mild cardiomegaly with left myocardic hypertrophy; calcification of the mitral valve and aortic cusps; adhesive fibrous pericarditis; scleroatrophic kidneys with cystic dialysis transformation; haemorrhagic colitis; pulmonary oedema; and inactive bronchiectasis in the medium lobe of the right lung. No malignancies or tuberculosis were found.

Microscopic examination of tissues fixed in $10 \%$ buffered formalin, disclosed abundant amorphous eosfnophilic material which stained with alkaline Congo red and showed apple-green dichroism under polarised light. The amyloid had infiltrated the vessel walls of visceral organs (gastrointestinal tract, liver, spleen, pancreas, heart, urinary bladder, and kidneys) and skin; muscular layers of the gastrointestinal tract and urinary bladder; and myocardium, pericardium, and peritoneum. Amyloid deposits were particularly heavy in the auricular myocardium.

In the vessel walls amyloid was found in the muscular layer and in the subendothelial space where it appeared as nodules protruding into the vascular lumen. An intense foreign body giant cell reaction was found around the scattered submesothelial nodules.

Immunohistochemical studies using the avidin-biotin complex method were performed on serial sections of the paraffin wax embedded samples of stomach, ventricular and auricular myocardium, pericardial and peritoneal nodules. Monoclonal antibodies to amyloid A (AA), and polyclonal $\beta_{2}-M$, prealbumin, $\kappa$ and $\lambda$ light chains (Dako) were applied. For positive controls, substitution of the antibodies with TRIS-buffered saline, and alkaline Congo red staining of tissue samples were also used.

Only anti-AA and $\beta_{2}-\mathrm{M}$ antibodies reacted positively with the amyloid. In the stomach both antibodies stained the amyloid of the muscularis propia with anti-AA showing a more diffuse pattern of staining than anti- $\beta_{2}$ $\mathrm{M}$; in subserosal nodules $\beta_{2}-\mathrm{M}$ was mainly observed in the periphery; AA appeared in the core (figure). In the vessels of all samples anti$\beta_{2}-\mathrm{M}$ seemed to be generally confined to the subendothelial amyloid, and anti-AA stained the other layers of the wall. In the myocardium the amyloid reacted positively only with anti-AA, while in the auricular myocardium both antibodies appeared intermingled.

Electron mycroscopic studies carried out on formalin fixed auricular myocardium showed interstitial curvilinear microfibrils 
Figure (a) Gastric wall: muscle layer and subserosal nodule are positively stained with anti-AA (avidin-biotin complex). (b) Gastric wall (serial section): positive staining with anti- $\beta 2-M$ in the periphery of the subserosal nodule, and in the muscular layer (avidinbiotin complex).
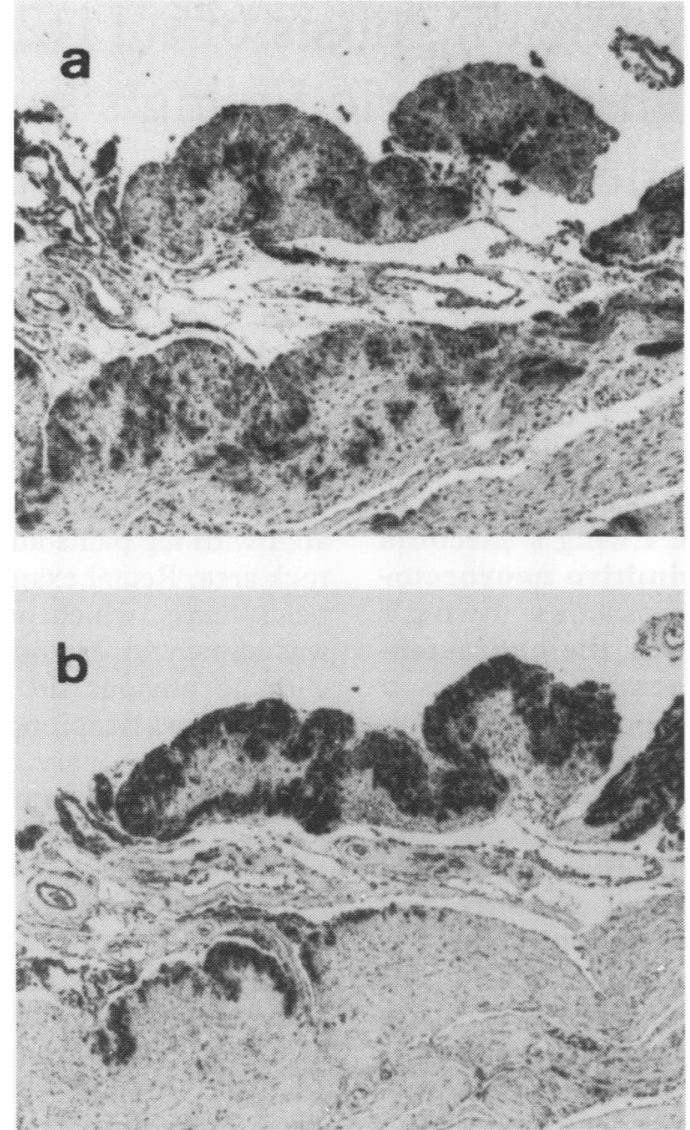

arranged in bundles characteristic of $\beta_{2}-\mathrm{M}$ amyloid, in addition to crossed straight microfibrils arranged haphazardly, characteristic of the other types of amyloid. ${ }^{6}$

\section{Discussion}

Dialysis amyloidosis seems to have a predilection for the osteoarticular system, ${ }^{1}$ but in some instances visceral amyloid deposits can cause serious clinical complications. ${ }^{34}$ In our patient clinical manifestations of visceral amyloidosis were absent, at least until the episode of heart failure that led her to death.

It is worth pointing out several findings in this case. Firstly, the results of the histological, immunohistochemical, and ultrastructural studies showed the presence of systemic deposits of both amyloids $\left(\beta_{2}-\mathrm{M}\right.$ and $\left.\mathrm{AA}\right)$ which happens only rarely. ${ }^{7}$ Secondly, both amyloids showed a distinctive tissular distribution, with $\beta_{2}-\mathrm{M}$ being preferentially located in the subendothelium of the vessels, as noted before, ${ }^{8}$ and surrounding the AA amyloid deposits in the mesothelial nodules. Finally, an intense giant cell reaction was present around the $\beta_{2}-\mathrm{M}$ amyloid deposits. Giant cell reaction to $\beta_{2}-\mathrm{M}$, a common finding in the synovium, has occasionally been described in visceral deposits. ${ }^{69}$

Several factors, such as chronic pyelonephritis, bronchiectasis, repetitive infections of the arteriovenous fistule, and haemodialysis could explain the presence of AA amyloid in this case, though it is difficult to ascribe its development to one of them. It seems unlikely that bronchiectasis could account for AA amyloidosis because of the absence of previous history and its inactive character. In a review of 45 consecutive necropsies with bronchiectasis we found AA amyloidosis in four cases, all of them with clinical and pathological evidence of active disease (unpublished data).

As regards chronic pyelonephritis, AA amyloidosis has scarcely been reported in the absence of stag horn calculi or spinal cord injury. ${ }^{10}$ No conditions were present in this case.

The patient had had repeated infections of the arteriovenous fistule for seven months before her death, but it is difficult to consider those infectious episodes as the cause of AA amyloidosis in such a short time.

A constant synthesis of AA protein induced by the leucocyte pyrogen produced by haemodialysis might be another possible mechanism for the development of AA amyloidosis in this patient.

We thank Mr M Hermida for kindly performing immunohistochemical techniques and Mr F Fuentes for his photographic assistance.

1 Kleinman KS, Coburn JW. Amyloid syndromes associated with hemodialysis. Kidney Int 1989;35:567-75.

2 Noel LH, Zingraff J, Bardin T, Atienza C, Kuntz D, Drueke T. Tissue distribution of dialysis amyloidosis. Clin Nephrol 1987;27:175-8.

3 Arakawa M, Gejoo F, Oohara K, Homma N. Systemic deposition of Beta-2 microglobulin amyloid. In: Gejyo F, Brancaccio D, Bardin T, eds. Dialysis amyloidosis. Milan: Wichtig Editore, 1989:111-8.

4 Maher ER, Hamilton Dutoit S, Baillod RA, Sweny P, Moorhead JF. Gastrointestinal complications of dialysis related amyloidosis. $\mathrm{Br} M e d \mathcal{F}^{1988 ; 297: 265-6}$.

5 Morita T, Kamimura A, Hirasawa Y. Amyloid deposits in patients on long-term hemodialysis are not always beta-2microglobulin related. Nephron 1988;50:171-2.

6 Takahashi S, Morita T, Koda Y, Murayama H, Hirasawa Y. Gastrointestinal involvement of dialysis-related amyloidosis. Clin Nephrol 1988;30:168-71.

7 Linke RP, Kunet U, Lobeck H, Hampl H, Eulitz M. Chemical analysis of beta ${ }_{2}$-microglobulin derived amyloid in patients on long-term hemodialysis. In: Isobe T Araki S, Uchino F, Kito S, Tsubura E, eds. Amyloid an amyloidosis. New York: Plenum, 1988:611-6.

8 Campistol JM, Cases A, Torras A, Soler M, MuñozGomez J, Montoliu J, et al. Visceral involvement of dialysis amyloidosis. Am $\mathcal{f}$ Nephrol 1987;7:390-3.

9 Mazanec K, McClure J, Bartley CJ, Newbould MJ, Ackrill P. Systemic amyloidosis of $\beta_{2}$-microglobulin type. $\mathcal{f}$ Clin Pathol 1992;45:832-3.

10 Caravaca F, Herrera JM, Pizarro JL, Arrobas M, Robles R, Saez-Santamaria J. Systemic amyloidosis (type AA) in end-stage renal failure patients due to chronic pyelonephritis. Nephron 1991;59:510-1. 